\title{
養鰻池における毠場の形式とその効果*
}

\author{
稲葉伝三郎・上 原 良 吾 \\ (1962 年4月 27 日受理)
}

\section{ON THE TYPES AND ROLES PLAYED BY THE RESTING POOL OF EEL-POND.}

\author{
Densaburo INABA and Ryogo UeHARA**
}

\begin{abstract}
Since the previous report in $1953^{12}$, the use of the resting pool in eel-pond has become popular, and almost all the ell-ponds in Kawashiri district (Fig. 1) are now equipped with it. The 86 eel-ponds at the district out of 204 were observed as to the size, area, water supply and utilization of vertical pump and agitator. For the 12 resting pools of different types selected, sudies were made on diurnal change of water temperature, disolved oxygen, $\mathrm{NH}_{4}-\mathrm{N}$ etc. Results are summerized as follows:

1. The resing pools are generally $40 \sim 70 \mathrm{~cm}$ in depth and take increasingly a form of rectangle and are supplied with well water mixed from creek (Table 1).

2. The resing pools measure $50 \sim 60 \mathrm{~m}^{2}$ in surface area or about $1.3 \%$ to $4,500 \mathrm{~m}^{2}$ of the rearing ponds.

3. The resting pools may be divided into 3 types by their water circulation: the running water type (Fig. 2), semi-circular type (Fig. 3) and circular type (Fig. 4).

4. During summer time, the water of creek or well supplied $40 \sim 70 \mathrm{l} / \mathrm{sec}$. in the pools at night, kept the temperature of pool water $4 \sim 6^{\circ} \mathrm{C}$ lower and the disolved oxygen $0.9 \sim 3.8$ $c c / l$ higher than those of the rearing pond.

5. There are no apparent trouble or difficulty in keeping $3.2 \sim 12$ tons of eel in a resting pool of $50 \sim 60 \mathrm{~m}^{2}$ at night which is supplied with above mentioned amounts of water and it saves safely the eel from their "gulping".
\end{abstract}

\section{粕言}

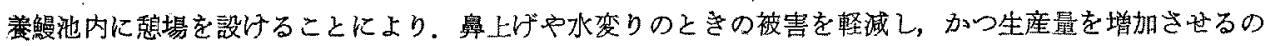
に徍立つことが知られている

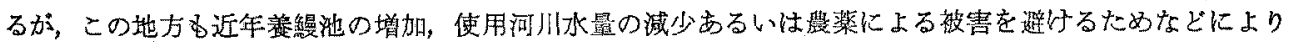
井戸水を利用することが多くなつてきた。またウナギを取上り゙る時も夜閒ウナギが䕀場内に集つたときに敖

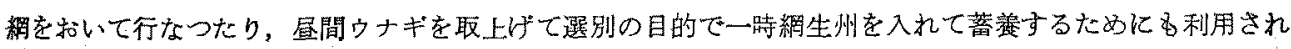

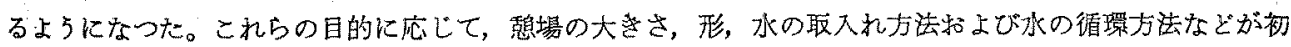
期の頃 ${ }^{1,5)}$ に比べて変化し，水利の不便な地方に措いて子利用され易い形式が多くなつてきている。

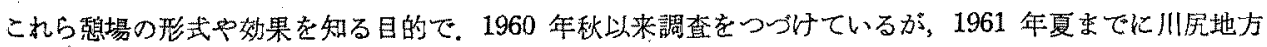

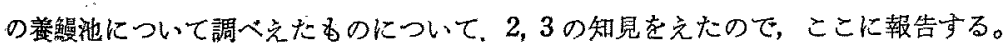

本調查には海貝正二・金子次男・增田文吾の 3 氏に種々御協力をいたたいた。溙原養殖漁業協同組合の久

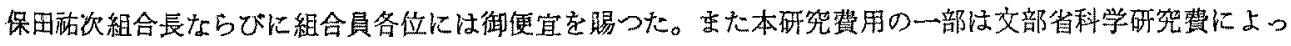
たるのである。本文に入るに先立ら深く感謝の意を表する。

$$
\text { 方法 }
$$

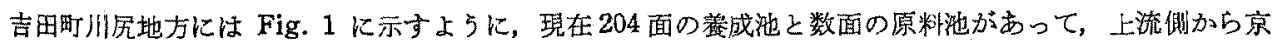

* 昭和 36 年 10 月 18 日，日本承座学会秋季大会にて発表。

** 東京水㽷大学 (Tokyo Univ. of Fish., Shiba Kaigandori 6, Minato-ku, Tokyo, Japan). 


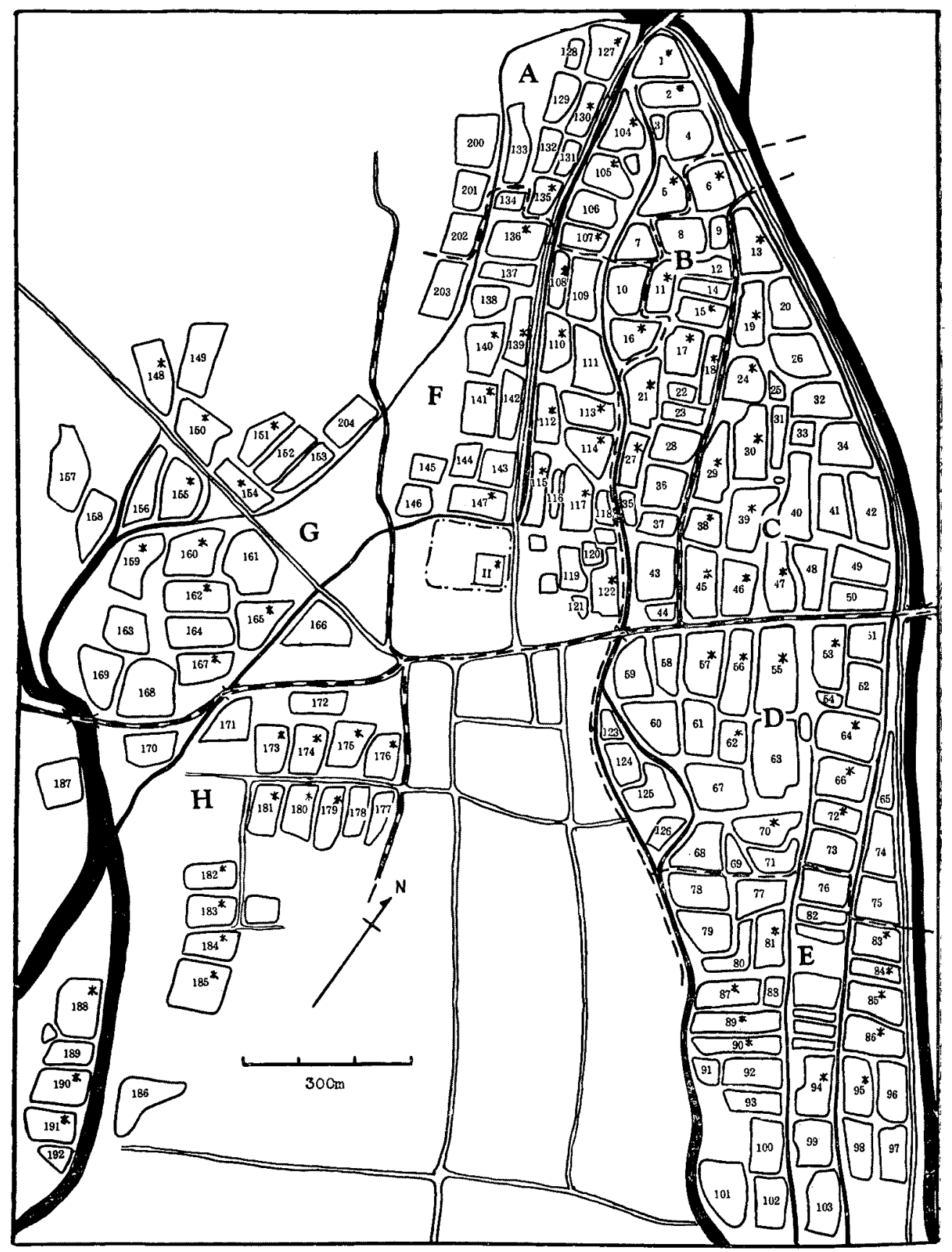

Fig. 1. The distribution map of the eel-pond at Kawashiri district, Yoshida, Shizuoka Prefecture. Letters show the area of the district; A. Kyoda-kami, B. Kyoda-shimo, C. Terada, D. O:subo, E. Hirashima-kami, F. Hirashima-shimo, G. Nishigahara-kami, H. Nishigahara-shimo. Figures show the number of ell-pond, and asterics show the eel-pond observed. 


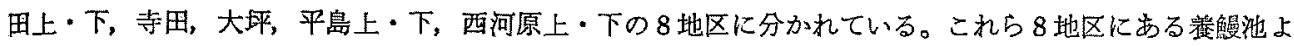

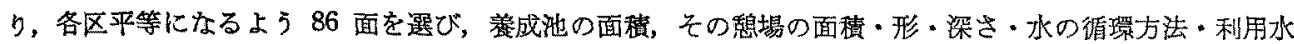
源・動力などを調べた。さらに稳場の形式の異なる 12 面について, 水温, $\mathrm{pH}$, 溶存酸素量, アンモニア量

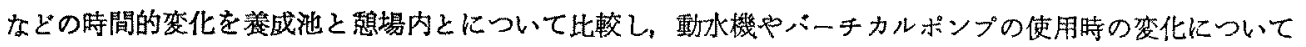
も調べた。

溶存酸素量はゥインクラー法， $\mathrm{pH}$ は比色法、アンモニア量はネスラー試薬による呈色を光䉓比色計によ り測定した。

\section{結果および考察}

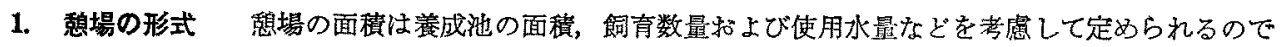
あるが，今回調査の 86 面については $20 \sim 135 \mathrm{~m}^{2}$ の䡶田で平均 $56.1 \mathrm{~m}^{2}$ であった。これをそれぞれの養成 池の面積 (2195 9072 $\left.\mathrm{m}^{2}\right)$ と比較すると $0.55 \sim 3.21 \%$ となり，平均 $1.24 \%$ となつている。馝場の梁さは 美成池をそのまま用い約 $40 \sim 70 \mathrm{~cm}$ であるが，測定した 11 池の平均は $58.6 \mathrm{~cm}$ となり，想場の容積は 20 50 $\mathrm{m}^{3}$ で平均 $33 \mathrm{~m}^{3}$ であつた。その形は正方形，長方形，台形，扇形，半円形，三角形，五角形，六角 形などであるが，近年動水機やバーチカルポンプなどを利用して㥎場の效果を高めるために長方形のすのが 多くなる傾向がある (Table 1)* 利用水源注前報"のとき河川水のみであつたが, 今回の調査では Table 1

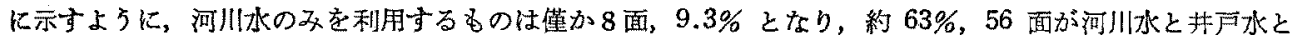
を銿用している。とくに下流側の西河原地区では，ほとんどが井戸水のみか，井戸水を主として河川水を法

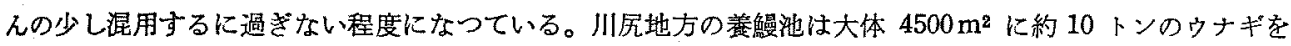
收容するるのが多いが2゙，想場に利用する水量は每秘約 22 70lであつた。この地方の井戸一つからパーチ

Table 1. The distribution of the form, water supply and type of water circulation in the resting pool of eel-pond at Kawashiri districts, Shizuoka Prefecture.

\begin{tabular}{|c|c|c|c|c|c|c|c|c|c|c|}
\hline \multicolumn{2}{|c|}{ Name of Area } & 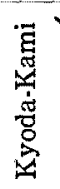 & 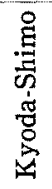 & 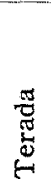 & $\begin{array}{l}\stackrel{\circ}{3} \\
\stackrel{0}{3} \\
0\end{array}$ & 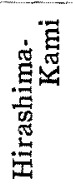 & 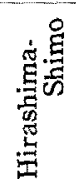 & 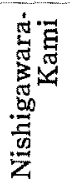 & 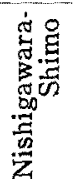 & 苑 \\
\hline \multicolumn{2}{|c|}{ Nos. of eel ponds observed } & 9 & 14 & 10 & 10 & 9 & 10 & 10 & 14 & 86 \\
\hline \multirow{6}{*}{$\begin{array}{l}\text { Form of } \\
\text { resting pool }\end{array}$} & Rectangule & 4 & 5 & 8 & 8 & 4 & 6 & 9 & 6 & 50 \\
\hline & Square & 0 & 1 & 1 & 2 & 3 & 0 & 0 & 2 & 9 \\
\hline & Triangule & 2 & 1 & 1 & 0 & 0 & 0 & 0 & 1 & 5 \\
\hline & Fan shape & 2 & 1 & 0 & 0 & 0 & 2 & 0 & 3 & 8 \\
\hline & Trapezoid & 0 & 5 & 0 & 0 & 1 & 1 & 1 & 0 & 8 \\
\hline & Others & 1 & 1 & 0 & 0 & 1 & 1 & 0 & 2 & 6 \\
\hline \multirow{3}{*}{ Water supply } & Creek & 2 & 4 & 0 & 0 & 1 & 1 & 0 & 0 & 8 \\
\hline & Well & 0 & 0 & 0 & 0 & 0 & 0 & 9 & 13 & 22 \\
\hline & Creek + Well & 7 & 10 & 10 & 10 & 8 & 9 & 1 & 1 & 56 \\
\hline \multirow{3}{*}{$\begin{array}{l}\text { Type of water } \\
\text { circulation }\end{array}$} & Running water & 3 & 6 & 5 & 5 & 5 & 2 & 1 & 0 & 27 \\
\hline & Semi-circular & 5 & 2 & 2 & 3 & 1 & 4 & 2 & 6 & 25 \\
\hline & Circular & 1 & 6 & 3 & 2 & 3 & 4 & 7 & 8 & 34 \\
\hline
\end{tabular}

*楒場の注水部に通常ストックと呼ら細長い水の流通の上い場所（多くはコンクリート造り）を付設する すのもある。 


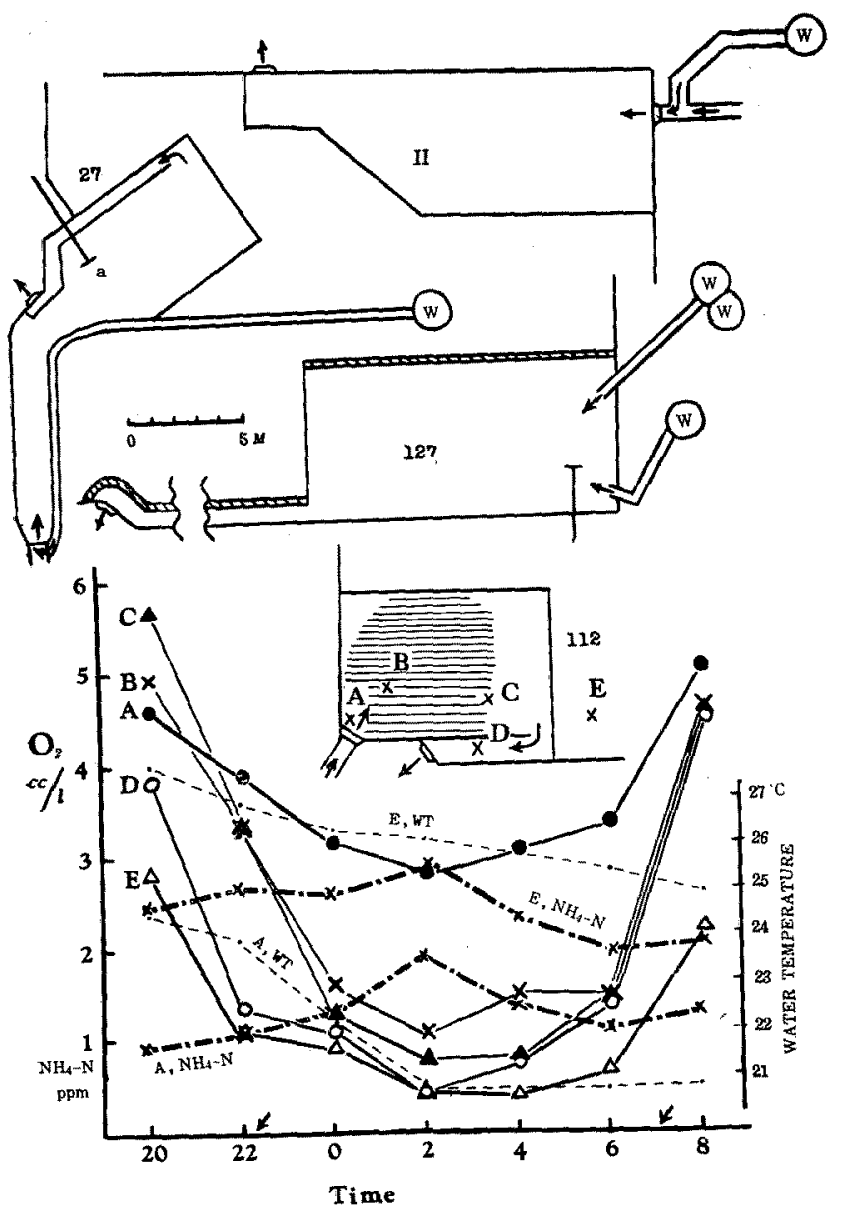

Fig. 2. Upper figures illustrating four examples of resting pool (running water type). Figures are same as in Fig. 1; W-Well, a-agitator.

Lower figure diurnal change of water temperature, disolved oxygen and $\mathrm{NH}_{4}-\mathrm{N}$ in the resing pool and the rearing pond No. 112 measured on 29 30, Aug., 1961. Hatches show the area eel swarmed at night in the resting pool. A-E show the points of measurements. WT-Water temperature.
カルポンプを用いて没文上げられる 水量注每利 $15.6 \sim 24.51$ ですつたか ら湧水量の多い井戸が 2 3 あれば，

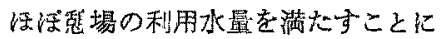
なる。河川止を十分利用できる孳鰻 池で是，夏多くの池が同特に番上げ をする場合には河川皮が不足するこ とがあるので, 2 3の井戸を併設す るものが多くなつている。なた㒭場

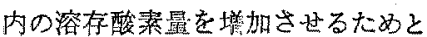
使用水量を節約子るために，愁場内 に鱾水機，バーチカルポンプ季たは ヒニガルポンプを 1 2 台設置する あのがある。これらを水の循環方式 加胃ると，便宣上流水式，半循燢 式轮上び循昶式の三つに大別するこ とができる。

流水式はすでに報告”したよ5に 河川水の豊富な地域にできたもので 方つて，河川水案た注并水だけを 流入させるものである。この形式の

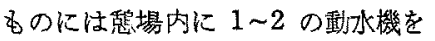

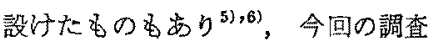
で注 27 面，31.4\%を占めていた

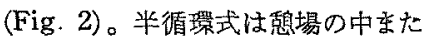
は注水口にバーキカルポンブを設置 して，その中の水の一部を德環させ るあのであつて (Fig. 3)，今回の調 查で活 25 面, $29.1 \%$ を占めてい た。循䍜式任憩嚗内の排水口に近い ところに 1 2 台のバーチカルポン プかとニガルポンプを設置して，一 度使用した水を再び利用する形式の ものである (Fig. 4)。この形式は使 用河川水の少ない地域に見られるるのであるが，今回の調查では 34 面，39.5\%をなり，この形式のるのが 增加していることを示している。これらの動力は機械 1 台につき1 馬力のものが大部分であるが，井戸から の掦水汇泣 2 3 馬力を用いている。発政機を用意しているが，多くは霆力によるるのである。その使用量

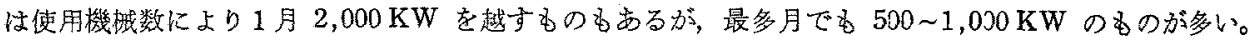

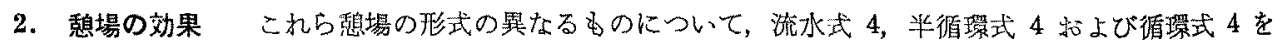

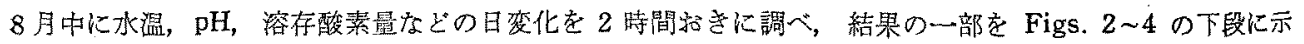
Lた。

8 月に和叮る飼育池の水温日变化法 $14 \sim 16$ 時に最高の $30 \sim 32^{\circ} \mathrm{C}$ を示し，4 6 時に $25 \sim 28^{\circ} \mathrm{C}$ に低下す

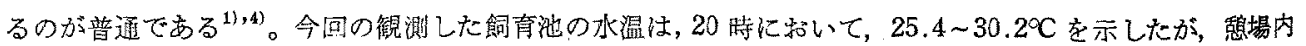


では河川水 $\left(2 丁 .2 \sim 23.8^{\circ} \mathrm{C}\right)$ または 井戸水 $\left(18.3 \sim 21.5^{\circ} \mathrm{C}\right)$ を注入する と，その注入量に応じ多少の遅速が あっても，次第にその使用水の水温 まで低下してくる。4 時に牧ける両 者の水温差は 3.8 6.5 $5^{\circ} \mathrm{C}$ を示し, 0 6 時の間でる $4 \sim 5^{\circ} \mathrm{C}$ の差が常に 見られた (Figs. 2 4)。

溶存酸素舅の日交化は日中は植物 プランクトンの同化作用によって, $10 \mathrm{cc} / l(200 \%)$ 以上にも達するが， 18 時から 4 時頃まで急に減少し, 0 㭙頃に $1 \mathrm{cc} / l(16 \%)$ 内外々なる ことが多い、飼有池の酸素量の減 少に伴なつてウナギは次第に墛場内 に入るのであるが，多くは 22 時頃 であって，飼育池の酸素髽湴ときに は $1.7 \sim 3.0 \mathrm{cc} / l$ (II, 150 号池) が 観测されたが，1 cc/lくらいのとき が多かつた。ウナギの奥上げ汇飼育 池の酸素量落 $1 \mathrm{cc} / l$ のときに見られ ることとよく一致していだ)。潰定 した 12 の飼育池の $0 \sim 6$ 時の酸素 量は $0.16 \sim 1.34$ 平均 $0.52 \mathrm{cc} / l(2.7$ 〜24.4\%) であつたが, 稳場内は推 定5 10 トンのウナギが入つていた のにもかかから势 $0.93 \sim 4.36$ 平均 $2.83 \mathrm{cc} / l(14.7 \sim 70.3 \%)$ の值を示 した。蒩場内への通水量は大体 $40 \sim$ $70 \mathrm{l} / \mathrm{s}$ であつた。このよ弓に想場内 では飼育池に比べ水温が低く, 酸素 量が多く，かつその内の水が常に流

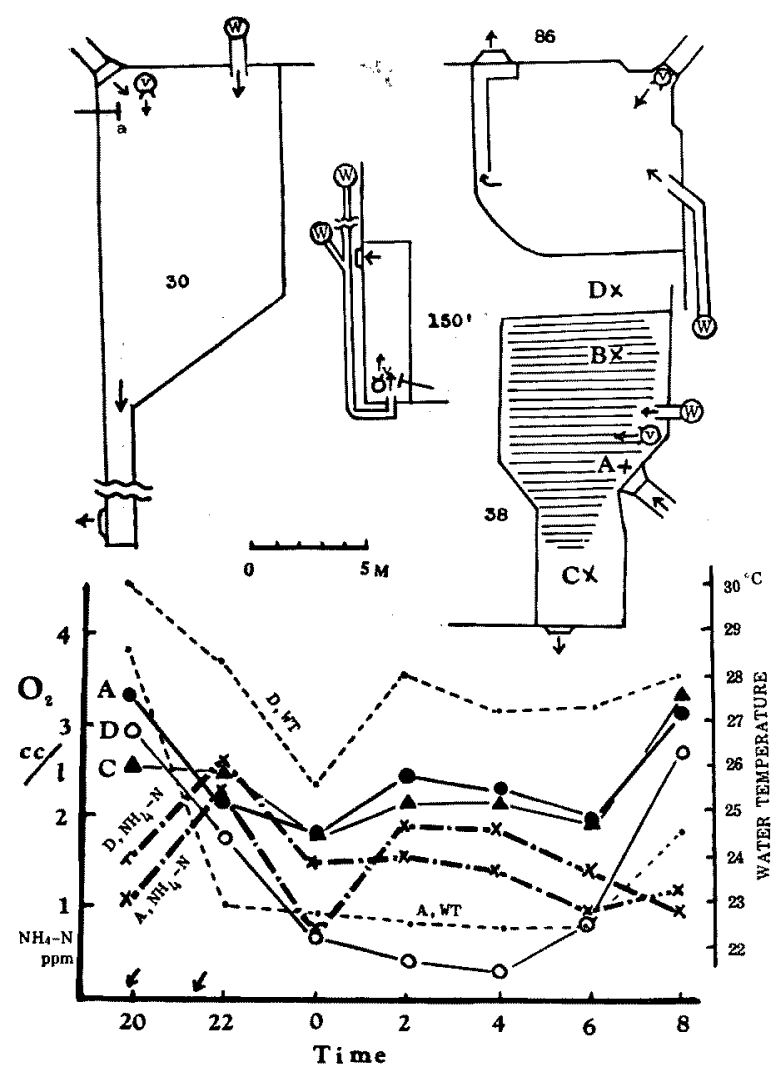

Fig. 3. Upper figures illustrating four examples of res. ting pool (semi-circular type). Figures are same as in Fig. 1; W-Well, a-agitator, v-vertical pump. Lower figure diurnal change of water temperature, disolved oxygen and $\mathrm{NH}_{4}-\mathrm{N}$ in the resting pool and the rearing pond No. 38 measured on $16 \sim 17$, Aug., 1961. Hatches show the area eel swarmed at night in the resting pool. A-D show the points of measurement. WT-Water temperature.

動しているので，㹟い面積内に晾いてる多量のウナギを安全に保つことになる゙”。とえば 114 号池の0〜 6 時の観測結果 (Fig. 4), 平均水温江飼育池 $26.4^{\circ} \mathrm{C}$, 想場 $22.0^{\circ} \mathrm{C} て ゙ 4.4^{\circ} \mathrm{C}$ 低く, 平均酸糸量は飼育池 $0.42 \mathrm{cc} / l$, 胡場 $4.1 \mathrm{cc} / l$ で約 $3.7 \mathrm{cc} / l$ 多く，その通水量注每秒約 $57 l$ (井戸水 $28+$ 河水 29 ) であつた。 ウナギの酸素消費量は $25^{\circ} \mathrm{C}$ に称いて $50 \mathrm{~g}$ のもので $76,100 \mathrm{~g}$ のるので $62 \mathrm{cc} / \mathrm{kg} / \mathrm{h}$ が疋当な值とされる

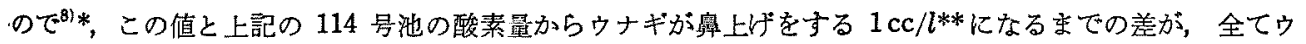
ナギの呼吸に使用しうるとして計算すると 1 尾平均 $50 \mathrm{~g}$ として約 8.5 トン平均 $100 \mathrm{~g}$ として約 10.5 トン のウナギの呼吸に支障がないことになる。観测した 12 の泍の想場について同様に計算すると平均 $50 \mathrm{~g} の$

* Dam は $4.44 \mathrm{cc} / \mathrm{kg} / \mathrm{h}$ を" ${ }^{81}$ ，角皆・久保田”) らは $38 \mathrm{cc} / \mathrm{kg} / \mathrm{h}$ の值を示している。これらの值では秘 場内のウナギの収容量がさらに多くなる。

*** 観测した 12 の想場の排水口付近での最低酸素量平均は $0.88 \mathrm{cc} / l(0.38 \sim 1.78)$ であつて, $1 \mathrm{cc} / l$ 内 外までに利用されるものと思われる。 


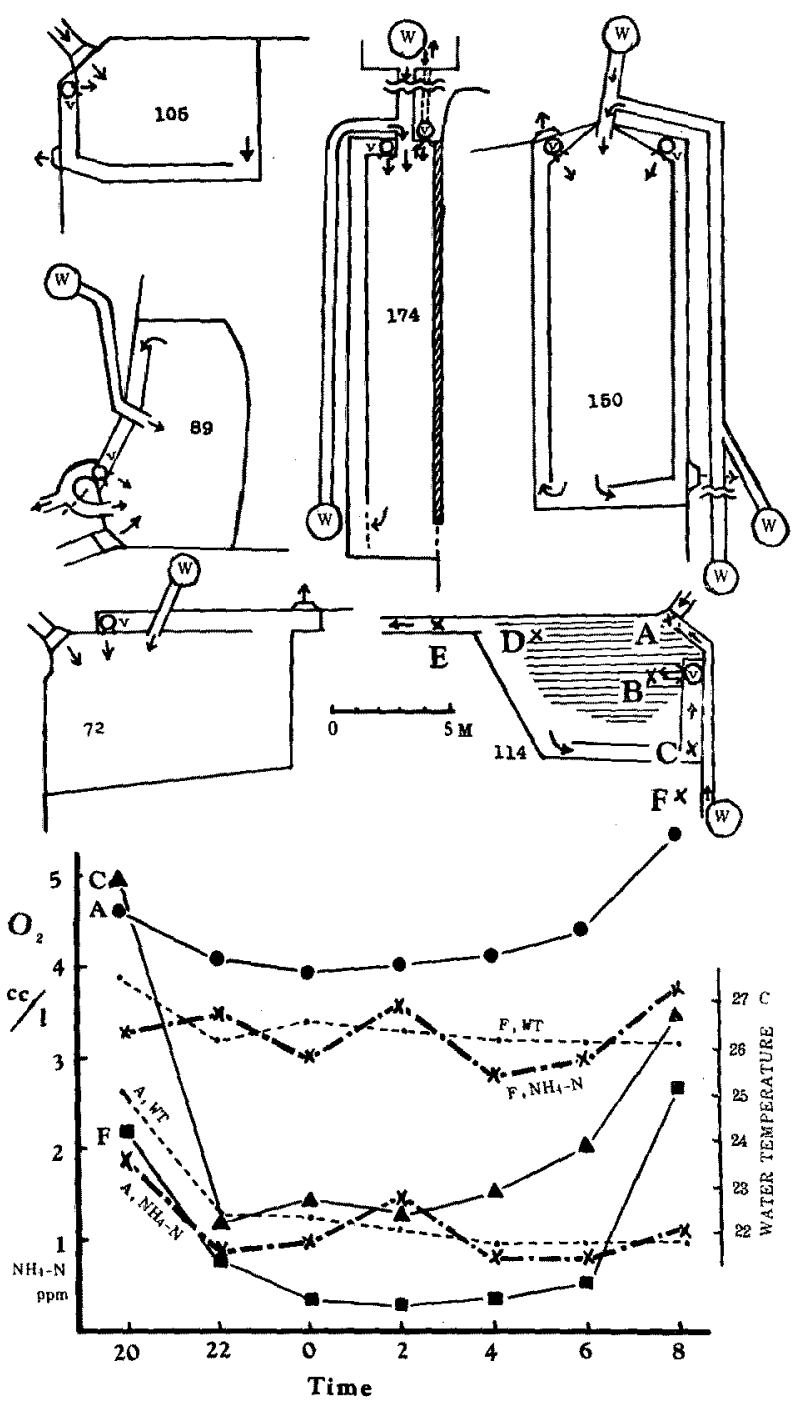

Fig. 4. Upper figures illustrating six examples of resting pool (circular type). Figures are same as in Fig. 1; W-Well, a-agitater, v-vertical pump.

Lower figure diurnal change of water temperature, disolved oxygen and $\mathrm{NH}_{4}-\mathrm{N}$ in the resting pool and the rearing pond No. 114 measured on $8 \sim 9$, Aug., 1961.

WT-Water temperature.

ウナギの場合は約 3.2 トン (108 号池) 9 トン (122 号泡)，平均 $100 \mathrm{~g}$ として約 4.5 トン 12トソを愁 場に収容するのに支障を生じないことになる。

$\mathrm{pH}$ の値の日変化は酸素量の增瑊によつていらじるしく異なり，日中は 9 以上の值を示すが，液間泩 7 内

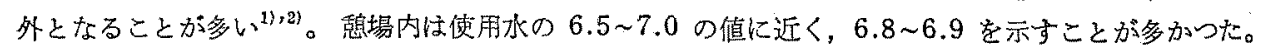

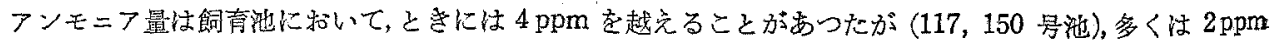


内外で日変化はとくにいらじるしいるのは見られなかつた。井戸水の 29 の調査では，いずれる $0.02 \mathrm{ppm}$

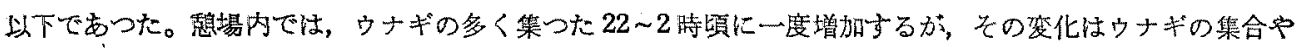

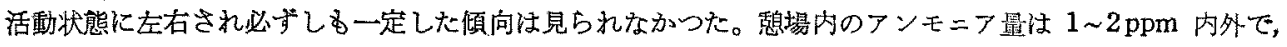
飼育池より少なく両者の差が 1 2 ppm であることが多い。

\section{摘要}

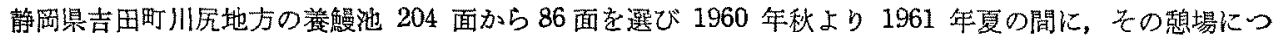
いて水梁・形・面稳・利用水源・使用動力などから形式を分けた。それらの形式の異なる 12 kついて，水 温・ $\mathrm{pH}$ ・溶存酸素量・アンモニフ量などの日变化からその効果を調べた。その結果次のことを知つた。

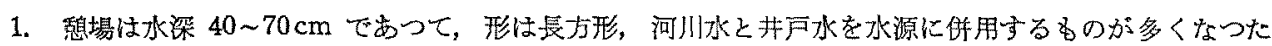
(Tabie 1)。

2. 想場の面積は飼育池 $4,500 \mathrm{~m}^{2}$ に対し $50 \sim 60 \mathrm{~m}^{2}$, 飼育池面耫に対し $1.3 \%$ くいが適当である。

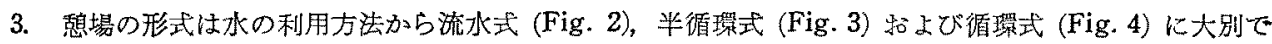
きる

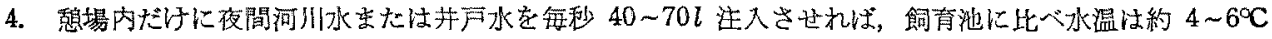
低く，酸素量注約 $0.9 \sim 3.8 \mathrm{cc} / l$ 多く保つことができる (Figs. 2 4)。

5. この注入水量によつて夜間ウナギ約 3.2 12 トンを悡場に収容するのに支障が生じない。したがつて 䝭育池のウナギを鼻上げから安全に保護することができる。

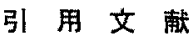

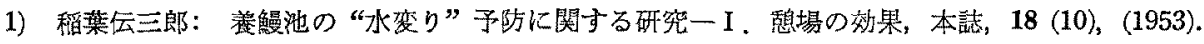

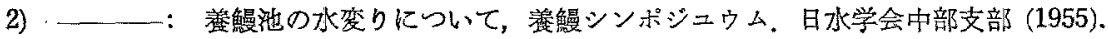

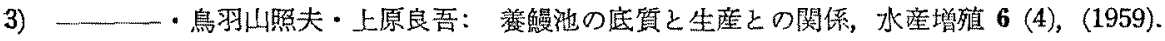

4) 板沢蛙男：ウナギの鼻上げ時の水中酸素量. 本誌, 26 (10)，(1960).

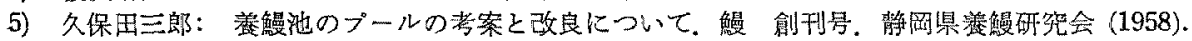

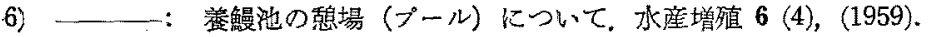

7) 角皆英明・久保田伸三：羡殖尚キギのイヶジメについて。水産增殖 6 (4)，(1959).

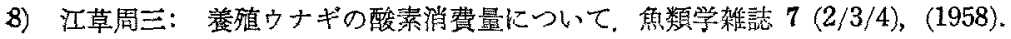

